\title{
Misconceptions about traumatic brain injuries among South African university students
}

\author{
C Pretorius, BSc Hons (Psych), MSc (Counselling psychology), PhD; M Broodryk, BA Hons (Psych) \\ Department of Psychology, Stellenbosch University, Stellenbosch, South Africa
}

Corresponding author: C Pretorius (chrismapretorius@sun.ac.za)

\begin{abstract}
Objective. To investigate the incidence and type of misconceptions about traumatic brain injuries (TBIs) harboured by university students. Method. A convenience sample of 705 university students were recruited and data were collected using an electronic survey. The link to the survey was sent via e-mail to all registered students at Stellenbosch University. The participants had to complete the Common Misconceptions about Traumatic Brain Injury (CM-TBI) questionnaire.

Results. The findings of this study suggest that the students subscribe to misconceptions from each of the 7 categories of misconceptions about TBIs. The mean percentages of misconceptions about TBIs were calculated and the amnesia (mean 49.7\%) and unconsciousness (mean 46.1\%) categories were identified as the categories about which the respondents had the most misconceptions, while the mean percentages of misconceptions were lower for the categories of recovery (mean 27.6\%), rehabilitation (mean 26.56\%), prevention (mean 20.8\%), brain injury sequelae (mean 18.7\%) and brain damage (mean 8.4\%).

Conclusion. Generally, these findings appear to be in keeping with previous literature, which suggests that misconceptions about TBIs are common among the general population. This study's identification of these misconceptions could help create awareness, provide a focus for information provision, and contribute to the development of educational intervention programmes tailored for the South African context.
\end{abstract}

S Afr J Psych 2013;19(3):75-79. DOI:10.7196/SAJP.436

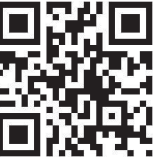

Worldwide, the most frequent cause of death and disability appears to be acquired brain injury. ${ }^{[1]}$ Traumatic brain injury (TBI) is a devastating condition that affects more than 10 million people a year worldwide. ${ }^{[2]}$ In the United States (US), Faul et al..$^{[3]}$ estimate that TBIs affect 1.7 million people annually. According to the National Health Laboratory Service, ${ }^{[4]}$ the reported number of new cases of TBIs in South Africa (SA) is estimated to be 89000 per annum. These high incidence rates suggest that TBIs are a serious public health concern worldwide, and SA is one of the countries with the highest rates of new cases.

The long-term consequences of a TBI are alarming. The Brain Injury Association of America ${ }^{[5]}$ estimates that 5.3 million people in the US need lifelong care and assistance with performing their daily activities after sustaining a TBI. A TBI can result in both implicit and explicit deficits: implicit, less observable problems include psychosocial, behavioural and cognitive problems (e.g. difficulties with memory, attention and concentration), changes in mood and even personality changes; whereas more observable deficits may include motor, sensory and speech problems. ${ }^{[6]}$ Obtaining new information and remembering it is typically the most severe deficit for individuals with a TBI. ${ }^{[7]}$

TBIs therefore merit adequate understanding by the general public, as well as healthcare professionals. However, despite the prevalence of TBIs and the consequences associated with them, a lack of knowledge and misconceptions about brain injuries appear to be common among family members and healthcare professionals involved in the care of individuals with $\mathrm{TBIs},{ }^{[8]}$ and even among people with personal experience with TBIs. ${ }^{[9]}$ The general public are not always informed about or do not always understand the physical, behavioural, cognitive and psychosocial consequences of TBIs. ${ }^{[1]}$

Thompson and Logue ${ }^{[10]}$ define misconceptions as ideas which cause us to incorrectly understand ideas, objects or events, and can be generally described as a mistaken belief or a myth about a specific concept. As described by Gouvier et al., ${ }^{[1]]}$ the most common misconceptions about TBIs relate to the use of seatbelts, the effects of unconsciousness, what individuals with TBIs are capable of doing, memory deficits, brain damage and recovery (how much recovery is possible and how long it takes). Most people also seem to have misconceptions about the long-term consequences of TBIs. ${ }^{[1,12]}$ According to a qualitative study by Swift and Wilson, ${ }^{[8]}$ some of the main misconceptions about the consequences of TBIs relate to how to identify a TBI, the visibility of the impairment, the diversity of TBI symptoms and expectations about the recovery process. Swift and Wilson ${ }^{[8]}$ also reported that people with mistaken beliefs about TBIs may unknowingly and indirectly discriminate against affected individuals, e.g. by having unrealistically high expectations of the individual.

Several studies have investigated misconceptions about TBIs among the general public and family members of people who sustained a TBI. ${ }^{[1,8,9,13-17]}$ Hux et al. ${ }^{[18]}$ focused on the knowledge and misconceptions about brain injury held by the general public, and establishing whether progress had been made in attempts to decrease misconceptions found in prior research. They found that almost half 
of the participants believed that: (i) after being knocked unconscious, most people wake up shortly and have no lasting effects; (ii) people with amnesia do not have trouble learning new things; and (iii) new learning following a TBI is no harder than remembering information that was mastered before the injury (misconceptions ranging from $23.58 \%$ to $48.48 \%$ ). With regard to the different categories, the most misconceptions were identified in the unconsciousness $(43.8 \%)$, memory $(54.7 \%)$ and recovery categories $(44.3 \%)$ while the least misconceptions were identified in the brain damage category (8.3\%).

Ernst et al. ${ }^{[13]}$ conducted a study among pre-nursing and nursing major students to compare the level of misconceptions between these two groups. The pre-nursing participants consisted of first- and secondyear nursing students and the nursing majors included third-, fourthand fifth-year nursing students. While the nursing major students were found to have fewer misconceptions compared with the pre-nursing students, the researchers found that substantial misconceptions do exist among nursing students in general, especially in the categories of recovery $(41.1 \%)$, unconsciousness $(28.7 \%)$ and amnesia (55.6\%), with the lowest amount of misconceptions relating to seatbelt use (14.28\%) and brain damage (6.6\%). However, another study found that nursing students did have fewer such misconceptions compared with university students with varying majors. ${ }^{[14]}$

Another recent study, conducted in Britain by Chapman and Hudson, ${ }^{[15]}$ revealed that most misconceptions about TBI relate to consciousness (60.6\%), the extent of memory deficits $(63.4 \%)$ and recovery (48.2). These misconceptions were evident regardless of participants' age, sex, level of education and prior experience or familiarity with a brain injury.

Unfortunately, misconceptions about TBIs are also evident among healthcare professionals, including school psychologists ${ }^{[16]}$ and speech therapists, ${ }^{[17]}$ whose scope of practice includes the assessment and treatment of individuals who survived TBIs.

So far, no studies have investigated misconceptions about TBIs in SA. Therefore, this study aimed to investigate the incidence and type of misconceptions about TBIs among students at a South African university.

\section{Method \\ Participants}

A convenience sampling method was employed to identify students at Stellenbosch University. Invitations to participate in the study were sent via university e-mail accounts to 21552 students (these e-mail addresses were obtained from the university's Division of Research and Planning). Each e-mail had a link that redirected the student to the site where the electronic survey could be completed.

To encourage participation, a financial incentive was offered in the form of a lucky draw. The initial response to the survey consisted of 1030 participants, a response rate of $4.78 \%$. However, some of the data had to be excluded because of incomplete questionnaires, because the survey was not set up in a way that required the individuals to answer all the items before they could submit the survey. This unfortunately led to the exclusion of 325 participants from the study, in order to use only complete datasets. In the end, a convenience sample of 705 university students was recruited. The majority of participants were female $(63 \%)$ and the sample consisted primarily of white students (76.2\%). More than half of the sample (53.5\%) were Afrikaans- speaking students, and more than a third (38.6\%) were Englishspeaking. The rest of the sample consisted of isiXhosa-speaking students (1.1\%) and students with other first languages (6.8\%). More than $60 \%$ of the sample participants were between the ages of 19 and 22. The frequency distribution of the sample by gender, race and home language is reported in Table 1.

\section{Instrument}

The online survey consisted of an informed consent form, a form for collecting biographical information about the participants and the Common Misconceptions about Traumatic Brain Injury questionnaire (CM-TBI). ${ }^{[9]}$ The CM-TBI is a 40 -item self-report measure developed to assess knowledge about TBIs. It is made up of key categories which include:

- prevention (including the wearing of seatbelts)

- brain damage

- brain injury sequelae (consequences of a TBI)

- unconsciousness

- amnesia

- the recovery process

- rehabilitation.

Out of the 40 items of this measure, 24 were developed by Gouvier et al. ${ }^{[11]}$ and the other 16 items were based on the clinical expertise of the lead author of Pappadis et al..$^{[9]}$ The questionnaire consists of true or false questions. For each question, participants had to indicate their agreement or disagreement along a 4-point Likert Scale ('true', 'probably true, 'probably false', and 'false').

Springer et al..$^{[19]}$ proposed two scoring systems for this questionnaire. The first dichotomises the categories of 'true' and 'false', scoring both the 'possibly true' and 'true' answers as correct and the 'false' and 'possibly false' answers as incorrect. The second consists of a stringent 4-point scale, where any response other than absolutely 'true' or 'false' is considered incorrect. The questionnaire was pilot tested among students from the psychology honours class to determine which

Table 1. Frequency distribution of the sample with respect to gender, race and language $(N=705)$

\begin{tabular}{ll}
\hline Biographical variables & $\boldsymbol{n}(\%)$ \\
\hline Gender & \\
Female & $444(63)$ \\
Male & $261(37)$ \\
Race & \\
Black & $49(7)$ \\
Coloured & $96(13.6)$ \\
Indian & $13(1.8)$ \\
White & $537(76.2)$ \\
Other & $10(1.4)$ \\
Home language & \\
Afrikaans & $377(53.5)$ \\
English & $272(38.6)$ \\
isiXhosa & $8(1.1)$ \\
Other & $48(6.8)$
\end{tabular}


scoring system to use. Twenty-one e-mail invitations were sent out and 5 students responded (response rate 23.8\%). A Cronbach's a internal reliability coefficient of 0.95 was calculated when the dichotomised categories was used to score the questionnaire, and $\alpha=0.327$ when the stringent 4-point scale was used. Therefore, dichotomised scoring was selected for the study. A Cronbach's a internal reliability coefficient of 0.84 has been reported for the CM-TBI in a sample of ethnic minorities with TBIs. ${ }^{[9]}$ The Cronbach's $\alpha$ coefficient for the current study was calculated as $\alpha=0.681$. According to Huysamen ${ }^{[20]}$ this indicates an acceptable level of internal consistency.

\section{Procedure}

After obtaining ethical approval by the Stellenbosch University Research Ethics Committee, and permission to conduct the study among university students from the university's Division of Institutional Research and Planning, students were invited by e-mail to take part in the online survey. The e-mail contained a description of the study, an informed consent form and a link to complete the online survey anonymously. Students also had the option to complete the survey in either Afrikaans or English. The back translation method was utilised to translate the CM-TBI into Afrikaans. The contact details of the university's counselling services were also provided at the end of the survey, should any of the participants feel that they needed counselling. The participants were also informed that they could withdraw from this study at any time during the survey. A window of 2 weeks was set for students to access the survey.

\section{Data analysis}

Data from the questionnaire were coded by the primary researcher and analysed using the Statistical Package for Social Sciences (SPSS) Version 18.0. The questionnaire responses were entered into the database and used to determine the percentage of university students with accurate and inaccurate beliefs about brain injury effects and recovery.

\section{Results}

\section{Misconception percentages for the total sample}

The mean percentages of misconceptions about TBIs were calculated and the amnesia (mean 49.7\%) and unconsciousness (mean 46.1\%) categories were identified as the categories about which participants had the most misconceptions (Table 2). The mean percentage for the categories of recovery (mean 27.6\%), rehabilitation (mean 26.56\%), prevention (mean 20.8\%), brain injury sequelae (mean 18.7\%) and brain damage (mean $8.4 \%$ ) suggest fewer misconceptions.

As mapped out in Table 2, items 18, 23, 24, 29 and 40 showed the highest percentages of misconceptions. Of the participants, 54\% believe that when people are knocked unconscious, most will wake up quickly with no lasting effects (item 18); $51.1 \%$ believe that the primary goal of brain injury rehabilitation is to increase physical abilities such as walking (item 40 ); $62.1 \%$ believe that a person with a brain injury may have trouble remembering events that happened before the injury, but usually does not have trouble learning new things; $70 \%$ seem to believe that people who sustained one brain injury are not more likely to have a second one (item 29); $88 \%$ believe that people with a brain injury can forget who they are and not recognise others, but be normal in every other way (item 24).

\section{Discussion}

Participants harboured misconceptions about each of the 7 identified categories. The categories that showed the most misconceptions were amnesia (49.7\%) and unconsciousness (46.1\%). Generally, these findings appear to be comparable to the findings of Hux et al. ${ }^{[1]}$ and Chapman and Hudson, ${ }^{[15]}$ which also indicated misconception rates ranging from $43.8 \%$ to $60.6 \%$ for amnesia and $54.7 \%$ to $63.4 \%$ for unconciousness, and that these 2 categories bore the most misconceptions. Participants had the fewest misconceptions in the brain damage category $(8.4 \%)$, which is similar to the findings of Hux et al..$^{[1]}(8.3 \%)$ and Ernst et al..$^{[13]}(6.6 \%)$. Generally, these findings are in keeping with previous literature, which suggests that misconceptions about TBIs are common among the general population. ${ }^{[1,13,15]}$

Some misconceptions appear to be more common than others. Examples of the more common misconceptions include the belief that when people are knocked unconscious, most will wake up quickly with no lasting effects ( $54 \%$ v. rates ranging from $48.11 \%$ to $59.28 \%$ in previous studies) ${ }^{[1,11]}$ and the misconception that the primary goal of brain injury rehabilitation is to increase physical abilities such as walking (51.1\% v. $65.5 \%$ in previous studies) ${ }^{[9]}$ A large number of participants appear to believe that a person with a brain injury may have trouble remembering events that happened before the injury, but usually does not have trouble learning new things ( $62.1 \%$ v. $49.8 \%$ $79.3 \%$ in previous studies). ${ }^{[1,9,13,14]}$ Furthermore, a substantial number seemed to believe that people who have had 1 brain injury are not more likely to have a second one (70\% v. $71.3 \%$ to $83.4 \%$ in previous studies). ${ }^{[11,13,14]}$ Finally, $88 \%$ of the participants seemed to believe that individuals with a brain injury can forget who they are and not recognise others, but be normal in every other way (v. 82.35\% - 93.4\% in previous studies). ${ }^{[1,11,13]}$ Thus, the findings of this study are be similar to the findings of several previous ones. ${ }^{[1,9,11,13,14]}$

Although this study did not aim to investigate why certain misconceptions about brain injury are reported more than others, the literature that has been reviewed speculates about the primary sources of information on head injury to which individuals have been exposed. Studies have identified popular media (such as television talk shows, movies, magazines, soap operas, daily newspapers and books) as the primary source of information, and participants in a number of studies indicated that their knowledge about brain injury had been informed by the media. ${ }^{[1,11,12,15]}$ For example, very few movies represent memory impairments accurately (e.g. 'Finding Nemo', 'Memento'), while most movies portray types of amnesia that are in fact neurologically impossible (e.g. '50 First Dates', 'Clean Slate'). ${ }^{[21]}$ Hux et al. ${ }^{[1]}$ list several participant remarks such as 'I saw that once in a movie' or 'It happened in my soap opera' attached to amnesia-related responses. Although the primary aim of the media is to entertain, not to educate, this illustrates the immense role the media has played in the development of misconceptions about brain injury.

\section{Study limitations}

The study consisted of a convenience sample of university students. Its findings cannot be generalised beyond this population, and it would be inappropriate to generalise the results to individuals with relatively low levels of formal education or from particularly deprived socioeconomic backgrounds. It would be advisable to replicate this study in a randomly selected cross-sectional sample of SA citizens. 
Table 2. Number of participants with misconceptions about TBIs: Items of the CM-TBI questionnaire

\begin{tabular}{|c|c|c|}
\hline Category & Item $($ true $(\mathrm{T}) /$ false $(\mathrm{F}))$ & $\begin{array}{l}\text { Respondents with } \\
\text { misconceptions } \\
n(\%)\end{array}$ \\
\hline \multirow[t]{5}{*}{ Prevention } & 1. You don't need seatbelts as long as you can brace yourself before a crash (F) & $28(4)$ \\
\hline & 2. It is more important to use seatbelts on long trips than in driving around town $(\mathrm{F})$ & $94(13.4)$ \\
\hline & 3. It is safer to be trapped inside a wreck than to be thrown clear $(\mathrm{T})$ & $293(41.6)$ \\
\hline & 4. Wearing seatbelts causes as many injuries as it prevents $(\mathrm{F})$ & $170(24.1)$ \\
\hline & Mean (\%) & $147(20.8)$ \\
\hline \multirow[t]{5}{*}{ Brain damage } & 5. A head injury can cause brain damage even if the person is not knocked out $(\mathrm{T})$ & $45(6.3)$ \\
\hline & 6. A little brain damage doesn't matter much, since people only use a part of their brains anyway (F) & $23(3.3)$ \\
\hline & $\begin{array}{l}\text { 7. It is obvious that someone has brain damage because they look different from people who don't have } \\
\text { brain damage (F) }\end{array}$ & $55(7.8)$ \\
\hline & 8. Whiplash injuries to the neck can cause brain damage even if there is no direct blow to the head (T) & $115(16.3)$ \\
\hline & Mean $(\%)$ & $59(8.4)$ \\
\hline \multirow{10}{*}{$\begin{array}{l}\text { Brain injury } \\
\text { sequelae }\end{array}$} & 9. It is common for people with brain injuries to be easily angered ( $\mathrm{T})$ & $302(42.8)$ \\
\hline & 10. It is possible that a person's personality will change after a brain injury $(\mathrm{T})$ & $79(11.2)$ \\
\hline & 11. Problems with speech, coordination, and walking can be caused by brain damage ( $\mathrm{T}$ ) & $11(1.6)$ \\
\hline & $\begin{array}{l}\text { 12. Problems with irritability and difficulties controlling anger are common in people who have had a } \\
\text { brain injury }(\mathrm{T})\end{array}$ & $143(20.3)$ \\
\hline & 13. Most people with brain damage are not fully aware of its effect on their behaviour (T) & $146(20.7)$ \\
\hline & $\begin{array}{l}\text { 14. Brain injury patients usually show a good understanding of their problems because they experience } \\
\text { them every day }(\mathrm{F})\end{array}$ & $299(42.4)$ \\
\hline & 15. Brain injuries may cause one to feel depressed, sad and hopeless (T) & $63(8.9)$ \\
\hline & 16. Drinking alcohol may affect a person differently after a brain injury $(\mathrm{T})$ & $63(14.4)$ \\
\hline & 17. It is common for people to experience changes in behaviour after a brain injury ( $\mathrm{T}$ ) & $43(6.1)$ \\
\hline & Mean (\%) & $132(18.7)$ \\
\hline \multirow[t]{4}{*}{ Unconsciousness } & 18. When people are knocked unconscious, most wake up quickly with no lasting effects (F) & $381(54)^{*}$ \\
\hline & 19. People in a coma are usually not aware of what is happening around them (T) & $328(46.6)$ \\
\hline & $\begin{array}{l}\text { 20. Even after several weeks in a coma, when people wake up, most recognise and speak to others right } \\
\text { away (F) }\end{array}$ & $265(37.6)$ \\
\hline & Mean (\%) & $325(46.1)^{*}$ \\
\hline \multirow[t]{5}{*}{ Amnesia } & $\begin{array}{l}\text { 21. People usually have more trouble remembering things that happen after an injury than remembering } \\
\text { things from before }(\mathrm{T})\end{array}$ & $242(34.4)$ \\
\hline & 22. Sometimes a second blow to the head can help a person remember things that were forgotten (F) & $100(14.1)$ \\
\hline & $\begin{array}{l}\text { 23. A person with a brain injury may have trouble remembering events that happened before the injury, } \\
\text { but usually does not have trouble learning new things (F) }\end{array}$ & $438(62.1)^{*}$ \\
\hline & $\begin{array}{l}\text { 24. People with brain injury can forget who they are and not recognise others, but be normal in every other } \\
\text { way (F) }\end{array}$ & $621(88)^{*}$ \\
\hline & Mean (\%) & $350(49.7)^{*}$ \\
\hline \multirow[t]{8}{*}{ Recovery } & 25. Recovery from a brain injury usually is complete in about 5 months (F) & $176(24.9)$ \\
\hline & $\begin{array}{l}\text { 26. Complete recovery from a severe brain injury is not possible, no matter how badly the person wants to } \\
\text { recover }(\mathrm{T})\end{array}$ & $331(46.9)$ \\
\hline & 27. Once a person is able to walk again, his/her brain is almost fully recovered (F) & $89(12.6)$ \\
\hline & 28. Slow recovery may continue even 1 year after injury $(\mathrm{T})$ & $53(7.6)$ \\
\hline & 29. People who have had one brain injury are more likely to have a second one (T) & $194(70)^{*}$ \\
\hline & 30. It is necessary for a person to go through a lot of physical pain to recover from a brain injury $(\mathrm{F})$ & $118(16.8)$ \\
\hline & 31. Once a person with a brain injury realises where they are, they will always be aware of this (F) & $189(26.8)$ \\
\hline & 32. A person who has recovered from a head injury is less able to withstand a second blow to the head (T) & $263(37.3)$ \\
\hline
\end{tabular}


Table 2 (continued). Number of participants with misconceptions about TBIs: Items of the CM-TBI questionnaire

\begin{tabular}{|c|c|c|}
\hline Category & Item (true/false) & $\begin{array}{l}\text { Respondents with } \\
\text { misconceptions } \\
n(\%)\end{array}$ \\
\hline & 33. A person who has a brain injury will be 'just like new' in several months (F) & $64(9.1)$ \\
\hline & $\begin{array}{l}\text { 34. Asking persons who have had a brain injury about their progress is the most accurate, informative way } \\
\text { to find out how they have progressed (F) }\end{array}$ & $209(29.7)$ \\
\hline & 35. It is good advice to remain completely inactive during recovery from a brain injury (F) & $130(18.5)$ \\
\hline & 36. Once a person recovering from a brain injury feels 'back to normal' the recovery process is complete $(\mathrm{F})$ & $71(10)$ \\
\hline & 37. How quickly a person recovers depends mainly on how hard he or she works at recovering $(\mathrm{F})$ & $340(48.2)$ \\
\hline & Mean (\%) & $194(27.6)$ \\
\hline \multirow[t]{4}{*}{ Rehabilitation } & 38. 'Cognitive' refers to thinking processes such as memory, attention and learning (T) & $33(4.7)$ \\
\hline & 39. 'Cognitive' refers to the ability to move your body (F) & $166(23.6)$ \\
\hline & 40. The primary goal of brain injury rehabilitation is to increase physical abilities such as walking (F) & $360(51.1)^{*}$ \\
\hline & Mean (\%) & $187(26.5)$ \\
\hline
\end{tabular}

As mentioned above, a limitation regarding the sample size could have been avoided had participants been required to answer all the items before they could submit the survey.

Furthermore, students were not expected to indicate their course of study. However, O'Jille et al. ${ }^{[14]}$ previously found fewer misconceptions among nursing students than university students with varying majors. It is possible that students from the health sciences might harbour fewer misconceptions than others, because of the medical foundation of their courses. This could be investigated in a follow-up study.

\section{Conclusion and recommendations}

As with most exploratory studies, the value of this project appears to be that it has taken the first step in attempting to understand the nature of the misconceptions about TBIs in the South African context. The findings of this study suggest that despite the high prevalence of TBIs in $\mathrm{SA},{ }^{[4]}$ university students do not always seem to be informed about or to understand the physical, behavioural, cognitive and psychosocial consequences of TBIs or the range of services needed by individuals who suffer from them. This study indicates that it is necessary to educate and to address these gaps in knowledge. The identification of the common TBI misconceptions listed above could be utilised to create awareness, provide a focus for information provision and contribute to the development of educational intervention programmes tailormade for the South African context.

This study also suggests avenues for future research. In particular, it is necessary to replicate this study with a more representative sample, and in samples with a wider age range or stratified according to gender, ethnicity, socioeconomic status and education. It could also be helpful to investigate the misconceptions about TBIs among healthcare professionals who work closely with individuals who have suffered a TBI.

\section{References}

1. Hux K, Schram CH, Goeken T. Misconceptions about brain injury: A survey replication study. Brain Inj 2006;20(5):547-553. [http://dx.doi.org/10.1080/02699050600676784]
2. Hyder AA, Wunderlich CA, Puvanachandra PG, Gururaj G, Kobusingye OC. The impact of traumatic brain injuries: A global perspective. NeuroRehabilitation 2007;22:341-353.

3. Faul M, Xu L, Wald MM, Coronado VG. Traumatic Brain Injury in the United States: Emergency Department Visits, Hospitalisations and Deaths 2002-2006. Atlanta: Centers for Disease Control and Prevention and National Center for Injury Prevention and Control, 2010. http://www.cdc.gov/ traumaticbraininjury/pdf/blue_book.pdf (accessed 30 May 2011).

4. National Health Laboratory Service. World Head Injury Awareness Day. Johannesburg: NHLS, 2011 (updated 2012). http://www.nioh.ac.za/?page=topical\&id=13\&rid=56 (accessed 30 May 2011).

5. Brain Injury Association of America. Traumatic Brain Injury: Prevalence, External Causes, and Associated Risk Factors. Olympia: Washington State Department of Health, 2011. http://www.doh. wa.gov/Portals/1/Documents/Pubs/346024.pdf (accessed 2 July 2011).

6. Guilmette TJ, Paglia MF. The public's misconceptions about traumatic brain injury: A follow up survey. Arch Clin Neuropsychol 2004;19(2):183-189. [http://dx.doi.org/10.1016/S0887-6177(03)00025-8]

7. Novack T. What to expect after TBI. Bakersfield: Centre for Neuro Skills, 2013. http://www.neuroskills. com/whattoexpect.shtml (accessed 30 May 2011).

8. Swift TL, Wilson SL. Misconceptions about brain injury among the general public and nonexpert health professionals: An exploratory study. Brain Inj 2001;15(2):149-165. [http://dx.doi. org/10.1080/026990501458380]

9. Pappadis MR, Sander AM, Struchen MA, Leung P, Smith DW. Common misconceptions about traumatic brain injury among ethnic minorities with TBI. J Head Trauma Rehabil 2010;26(4):301-311. [http://dx.doi.org/10.1097/HTR.0b013e3181e7832b]

10. Thompson F, Logue S. An exploration of common student misconceptions in science. International Education Journal 2006;7(4):553-559.

11. Gouvier WD, Prestholdt PH, Warner MS. A survey of common misconceptions about head injury and recovery. Arch Clin Neuropsychol 1988;3(4):331-343. [http://dx.doi.org/10.1016/08876177(88)90046-7]

12. Willer B, Johnson WE, Rempel RG, Linn R. A note concerning misconceptions of the general public about brain injury. Arch Clin Neuropsychol 1993;8(5):461-465. [http://dx.doi.org/10.1016/08876177(93)90009-P]

13. Ernst WJ, Trice AD, Gilbert JL, Potts H. Misconceptions about traumatic brain injury and recovery among nursing students. J Head Trauma Rehabil 2009;24(3):213-220. [http://dx.doi.org/10.1097/ HTR.0b013e3181a7ecd8]

14. O'Jile JR, Ryan LM, Parks-Levy J, et al. Effects of head injury experience on head injury misconceptions. International J Rehabil Health 2007;3:61-67.

15. Chapman RC, Hudson JM. Beliefs about brain injury in Britain. Brain Inj 2010;24(6):797-801. [http:// dx.doi.org/10.3109/02699051003709607]

16. Evans K, Hux K, Chleboun S, Goeken T, Deuel-Schram C. Persistence of brain injury misconceptions among speech language pathology graduate students. Contemp Issues Commun Sci Disord 2009;36:166-173.

17. Hooper SR. Myths and misconceptions about traumatic brain injury: Endorsements by school psychologists. Exceptionality 2006;14(3):171-182. [http://dx.doi.org/10.1207/s15327035ex1403_5]

18. Hux K, Walker M, Sanger D. Traumatic brain injury: Knowledge and self-perceptions of school speech-language pathologists. Lang Speech Hear Serv Sch 1996;27:171-180.

19. Springer JA, Farmer JE, Bouman DE. Common misconceptions about traumatic brain injury among family members of rehabilitation patients. J Head Trauma Rehabil 1997;12(3):41-50. [http://dx.doi. org/10.1097/00001199-199706000-00005]

20. Huysamen GK. Psychological Measurement: An Introduction with South African Examples. 3rd ed. Pretoria: Van Schaik, 1996.

21. Baxendale S. Memories aren't made of this: Amnesia at the movies. Br Med J 2004;329(7480):14801483. [http://dx.doi.org/10.1136\%2Fbmj.329.7480.1480] 